\title{
Article \\ Voluntary Wheel Running Partially Compensates for the Effects of Global Estrogen Receptor- $\alpha$ Knockout on Cortical Bone in Young Male Mice
}

\author{
Rebecca K. Dirkes ${ }^{1}$, Nathan C. Winn ${ }^{1,2}$, Thomas J. Jurrissen ${ }^{1}$, Dennis B. Lubahn ${ }^{3,4}$, Victoria J. Vieira-Potter ${ }^{1}$, \\ Jaume Padilla ${ }^{1,4,5}$ and Pamela S. Hinton $1, *,+$ \\ 1 Nutrition and Exercise Physiology, University of Missouri, Columbia, MO 65211, USA; \\ rdmr6@umsystem.edu (R.K.D.); nathan.winn@Vanderbilt.edu (N.C.W.); tjjmy9@umsystem.edu (T.J.J.); \\ vieirapotterv@missouri.edu (V.J.V.-P.); padillaja@missouri.edu (J.P.) \\ 2 Department of Molecular Physiology and Biophysics, Vanderbilt University, Nashville, TN 37203, USA \\ 3 Department of Biochemistry, University of Missouri, Columbia, MO 65211, USA; lubahnd@missouri.edu \\ 4 Child Health, University of Missouri, Columbia, MO 65211, USA \\ 5 Dalton Cardiovascular Research Center, University of Missouri, Columbia, MO 65211, USA \\ * Correspondence: hintonp@missouri.edu; Tel.: +1-573-882-4137; Fax: +1-573-884-4885 \\ $\dagger$ The author has nothing to disclose.
}

check for

updates

Citation: Dirkes, R.K.; Winn, N.C.; Jurrissen, T.J.; Lubahn, D.B.;

Vieira-Potter, V.J.; Padilla, J.; Hinton, P.S. Voluntary Wheel Running Partially Compensates for the Effects of Global Estrogen Receptor- $\alpha$ Knockout on Cortical Bone in Young Male Mice. Int. J. Mol. Sci. 2021, 22, 1734. https://doi.org/10.3390/ ijms22041734

Academic Editor: Farzad Pakdel

Received: 27 January 2021

Accepted: 5 February 2021

Published: 9 February 2021

Publisher's Note: MDPI stays neutral with regard to jurisdictional claims in published maps and institutional affiliations.

Copyright: (c) 2021 by the authors. Licensee MDPI, Basel, Switzerland. This article is an open access article distributed under the terms and conditions of the Creative Commons Attribution (CC BY) license (https:// creativecommons.org/licenses/by/ $4.0 /)$.

\begin{abstract}
Estrogen receptor- $\alpha$ knockout (ERKO) in female, but not male, mice results in an impaired osteogenic response to exercise, but the mechanisms behind this ability in males are unknown. We explored the main and interactive effects of ERKO and exercise on cortical geometry, trabecular microarchitecture, biomechanical strength, and sclerostin expression in male mice. At 12 weeks of age, male C57BL/6J ERKO and WT animals were randomized into two groups: exercise treatment (EX) and sedentary (SED) controls, until 22 weeks of age. Cortical geometry and trabecular microarchitecture were measured via $\mu \mathrm{CT}$; biomechanical strength was assessed via three-point bending; sclerostin expression was measured via immunohistochemistry. Two-way ANOVA was used to assess sclerostin expression and trabecular microarchitecture; two-way ANCOVA with body weight was used to assess cortical geometry and biomechanical strength. ERKO positively impacted trabecular microarchitecture, and exercise had little effect on these outcomes. ERKO significantly impaired cortical geometry, but exercise was able to partially reverse these negative alterations. EX increased cortical thickness regardless of genotype. There were no effects of genotype or exercise on sclerostin expression. In conclusion, male ERKO mice retain the ability to build bone in response to exercise, but altering sclerostin expression is not one of the mechanisms involved.
\end{abstract}

Keywords: estrogen; estrogen receptors; exercise; sclerostin; bone health

\section{Introduction}

Estrogen is one of the most influential hormones in growth and maintenance of the skeleton across the entire lifespan in both males and females [1-5]. Estrogen actions are mediated primarily by estrogen binding with the nuclear estrogen receptor (ER), which is found in two isoforms, $\operatorname{ER} \alpha$ and $\operatorname{ER} \beta$. Bone expresses both $\operatorname{ER} \alpha$ and $\operatorname{ER} \beta$; however, $\mathrm{ER} \alpha$ tends to be more prevalent in cortical bone, whereas $\mathrm{ER} \beta$ is more widely distributed in cancellous bone [6]. Global ER $\alpha$ knock out (ERKO) decreased longitudinal bone growth in both male and female mice [7-9]. Male ERKO mice show reduced bone turnover compared to wild-type (WT) controls [10], resulting in alterations in cortical bone geometry associated with decreased bending strength, such as decreased cortical bone area and cortical thickness $[9,10]$. However, cancellous bone mineral density (BMD) and total cancellous bone are increased in male ERKO mice, due to increased trabecular number $[10,11]$. These differential responses to the loss of ER $\alpha$ in cortical versus cancellous bone are most likely due to the variable distribution of estrogen receptors [6]. 
Estrogen and estrogen receptors in bone play an important role in the skeletal response to mechanical loading [12,13]. ER $\alpha$ is directly involved in the osteoblast response to strain [14-16], and ER $\alpha$ is upregulated and activated after application of mechanical strain. In vitro, osteoblasts taken from male and female ERKO mice do not proliferate and respond to strain like osteoblast cultures from WT controls [17], and female ERKO mice had an impaired osteogenic response to exercise [18]. However, male ERKO mice had either no differences or increased osteogenic response to mechanical loading compared to WT controls $[19,20]$. This implies some type of compensatory mechanism that allows for an osteogenic response to mechanical loading in ERKO males, possibly through ER $\beta$ or androgen receptors in bone [21].

Another recently hypothesized role of estrogen in the skeletal response to mechanical loading is the downregulation of the protein sclerostin. Osteocytes express sclerostin, which is a competitive inhibitor of the canonical Wnt signaling pathway. Canonical Wnt signaling plays a key role in bone formation, as it increases transcription of several osteogenic genes (reviewed in [22,23]). Briefly, association of the Wnt molecule with its receptor, co-receptor lipoprotein receptor-related protein 5 or 6 (LRP 5/6) leads to the release of a transcription factor, $\beta$-catenin, into the cytosol. $\beta$-catenin can then translocate into the nucleus, where it activates the transcription of several osteogenic genes, especially those related to osteoblast differentiation, such as osteoprotegerin. Inhibition of the Wnt signaling pathway via sclerostin is associated with decreased bone growth [24]. Animal and cell culture models show that sclerostin expression in osteocytes is regulated by several external factors, including insulin-like growth factor-I, parathyroid hormone, androgens and estrogens, and mechanical loading [24]. In healthy animals, mechanical loading downregulates sclerostin expression and leads to osteogenesis [24,25]. However, the specific role of estrogen in the control of sclerostin expression, and the effects of estrogen status on the sclerostin-mediated skeletal response to mechanical loading is still unknown.

In women and female rodent models, estrogen status is inversely related to sclerostin expression, whether measured via serum sclerostin levels [26-28] or by sclerostin mRNA [29] or protein in the bone [30,31]. In osteoblasts derived from female mice, sclerostin expression was downregulated after the application of exogenous estrogen, and ER $\beta$ appeared to play a greater role in the regulation of sclerostin than ER $\alpha$ [14]. In older men, estrogen treatment lowered circulating levels of sclerostin [32], implying that the inverse relationship between estrogen and sclerostin is also present in males. However, because circulating levels of sclerostin may not reflect bone sclerostin expression [33], further studies looking at the effect of estrogen on bone sclerostin expression in males are warranted.

The essential role of estrogen in bone health throughout the life cycle has been wellestablished in both sexes. However, questions still remain regarding the relative importance of specific estrogen receptors, especially $\mathrm{ER} \alpha$, in osteocyte sclerostin expression and the osteogenic response to exercise in males. Here, we look at the effects of global ER $\alpha$ knockout and voluntary wheel running exercise on cortical geometry, trabecular microarchitecture, biomechanical strength, and osteocyte sclerostin expression in male mice. We hypothesized that ERKO animals would have impaired cortical geometry and biomechanical strength compared to WT animals, but that exercise could lead to partial improvements in cortical geometry and biomechanical strength in ERKO animals, and significant improvements in the WT animals. We also hypothesized that ERKO animals would have increased trabecular bone volume compared to WT animals. Finally, we hypothesized that ERKO animals would have higher sclerostin expression than WT animals, and that exercise would downregulate sclerostin only in the WT groups. 


\section{Results}

\subsection{Animal Characteristics}

The metabolic characteristics of these animals have been previously published as part of a larger study [34], and the results have been summarized in Table 1. Briefly, exercise significantly decreased body mass $(p=0.001)$ and body fat percentage $(p=0.004)$, and increased average weekly food intake $(p=0.001)$, regardless of genotype (Table 1$)$. Exercise also significantly decreased LDL cholesterol, triglycerides, and leptin [34]. There was no difference in running distance between groups provided with running wheels [34]. ERKO animals had significantly higher LDL and total cholesterol compared to WT animals [34]. There was no effect of ERKO or exercise status on fasting blood glucose or insulin levels or HOMA-IR [34].

Table 1. Metabolic characteristics.

\begin{tabular}{|c|c|c|c|c|c|}
\hline \multirow[b]{2}{*}{ Outcome } & \multicolumn{2}{|c|}{ WT } & \multicolumn{2}{|c|}{ ERKO } & \multirow[b]{2}{*}{$p$-Value } \\
\hline & SED & EX & SED & EX & \\
\hline Body Mass (g) & $39.63 \pm 1.70$ & $33.06 \pm 1.77 *$ & $41.52 \pm 1.70$ & $36.39 \pm 1.58 *$ & $\begin{array}{c}\text { G: } 0.129 \\
\text { E: } 0.001 \\
G^{*} E: 0.670\end{array}$ \\
\hline Body Fat (\%) & $32.28 \pm 2.33$ & $22.96 \pm 2.64 *$ & $33.22 \pm 2.33$ & $27.56 \pm 2.21 *$ & $\begin{array}{c}\text { G: } 0.254 \\
\text { E: } 0.004 \\
G^{*} E: 0.450\end{array}$ \\
\hline Average Food Intake (g/week) & $9.09 \pm 0.21$ & $10.20 \pm 0.24$ * & $8.83 \pm 0.21$ & $9.60 \pm 0.20 *$ & $\begin{array}{c}\text { G: } 0.054 \\
\text { E: } 0.001 \\
G^{*} E: 0.432\end{array}$ \\
\hline
\end{tabular}

Data are means \pm SEM, $n=6-8$ per group. ERKO: ER $\alpha$ knock out; WT: wild type; EX: voluntary wheel running; SED: sedentary. G: genotype; E: exercise status; $\mathrm{G}^{*} \mathrm{E}$ : genotype by exercise interaction. ${ }^{*} p \leq 0.05 \mathrm{vs}$. SED of same genotype. There was a significant main effect of EX on body mass $((\mathrm{g}): \mathrm{EX}=34.73 \pm 1.19 ; \mathrm{SED}=40.58 \pm 1.18 ; p=0.001)$, body fat $((\%)$ : $\mathrm{EX}=25.26 \pm 1.72 ; \mathrm{SED}=32.75 \pm 1.65 ; p=0.004)$, and average food intake ( $(\mathrm{g} / \mathrm{wk})$ : $\mathrm{EX}=9.89 \pm 0.15 ; \mathrm{SED}=8.96 \pm 0.15 ; p=0.001)$.

\subsection{Tibial Cortical Geometry}

Tibial length was not different between groups. There was a main effect of genotype $(p=0.007)$ on Tt.Ar, with the ERKO animals having significantly lower Tt.Ar compared to the WT animals. There was a significant interaction $(p=0.05)$ between genotype and exercise, in that EX increased Tt.Ar only in the ERKO animals. ERKO animals had significantly lower robustness ( $\mathrm{Tt}$.Ar $/ \mathrm{Le}$ ) than WT counterparts $(p=0.01)$, but there was a significant interaction $(p=0.01)$ between genotype and exercise, in that EX increased robustness only in the ERKO animals. ERKO animals also had significantly lower Ma.Ar. than WT animals $(p=0.05)$. There was a main effect of genotype $(p=0.003)$ and exercise $(p=0.02)$ on Ct.Ar, with ERKO animals having lower Ct.Ar compared to WT and EX animals having higher $\mathrm{Ct}$.Ar than SED animals. There was a significant interaction $(p=0.05)$ between genotype and exercise on $\mathrm{Ct}$.Ar, in that $\mathrm{EX}$ increased $\mathrm{Ct}$.Ar significantly more in the ERKO animals than in the WT animals. There were main effects of genotype $(p=0.02)$ and exercise $(p=0.03)$ on Ct.Th, with ERKO animals having lower Ct.Th than WT animals, and EX animals having higher Ct.Th than SED animals. There were no differences in Ct.Ar/Tt.Ar, Imax/Imin ratio, or voxel intensity between groups (Figure 1). When body weight was not used as a covariate, the significant effect of genotype on Tt.Ar, Ma.Ar, $\mathrm{Ct}$.Ar remained, but the differences in Ct.Th were no longer significant, and there were no longer significant effects of exercise (data not shown). 

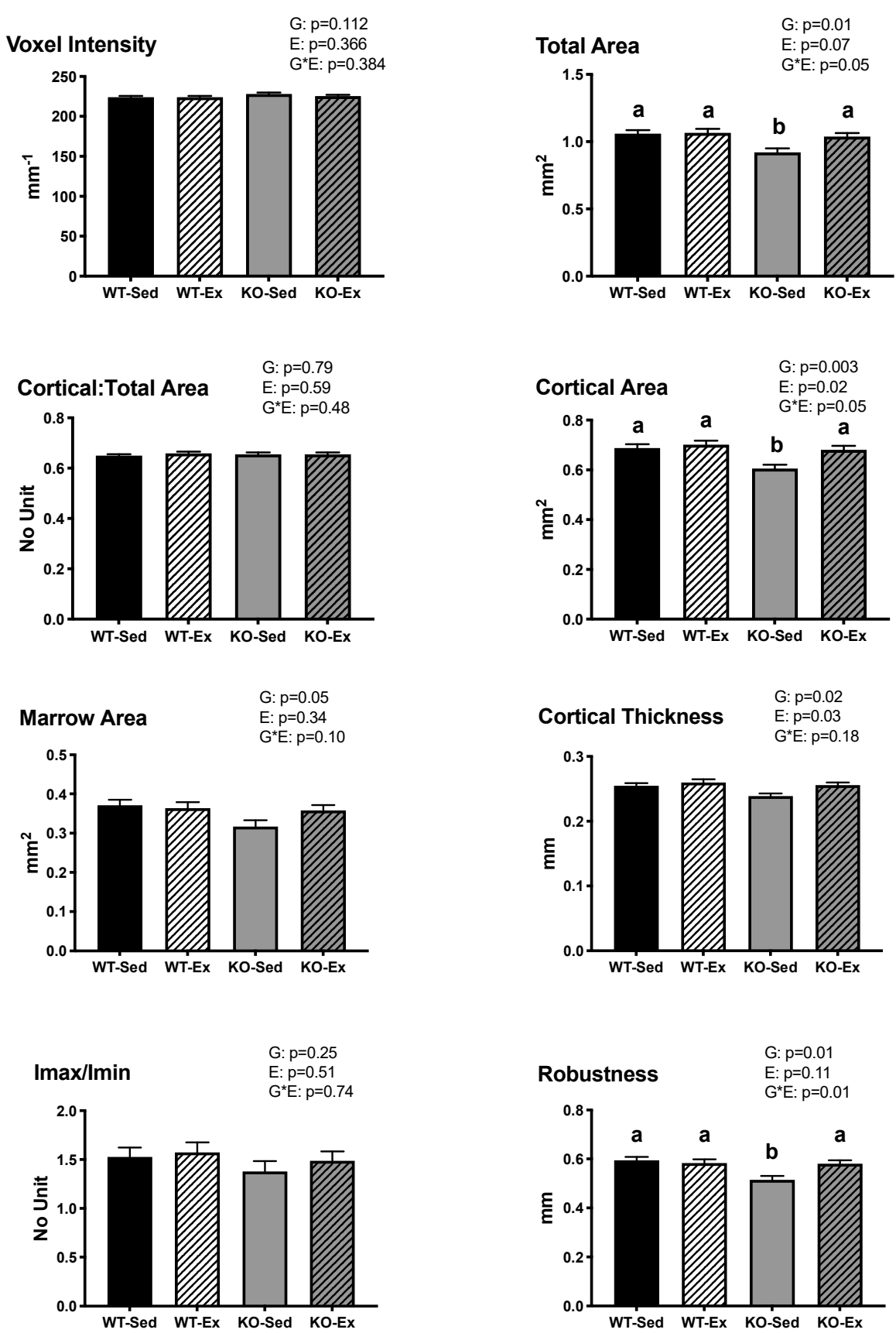

Figure 1. Tibial cortical geometry. Cortical geometry of the tibia. Data are adjusted means $\pm S E M$, $n=6-8$ per group ERKO: ER $\alpha$ knock out; WT: wild type; Ex: voluntary wheel running; Sed: sedentary. G: main effect of genotype ( $p \leq 0.05)$; EX: main effect of exercise status ( $p \leq 0.05)$; different letters $(a, b)$ denote significance $(p \leq 0.05)$ if $\mathrm{G}^{*} \mathrm{EX}$ interaction is present. There was a significant main effect of $\mathrm{G}$ on Tt.Ar $\left(\left(\mathrm{mm}^{2}\right)\right.$ : ERKO $\left.=0.980 \pm 0.019 ; \mathrm{WT}=1.063 \pm 0.019 ; p=0.007\right), \mathrm{Ct} . \mathrm{Ar}\left(\left(\mathrm{mm}^{2}\right): \mathrm{ERKO}=\right.$ $0.643 \pm 0.011 ; \mathrm{WT}=0.695 \pm 0.011 ; p=0.003), \mathrm{Ma} . \mathrm{Ar}\left(\left(\mathrm{mm}^{2}\right): \mathrm{ERKO}=0.337 \pm 0.010 ; \mathrm{WT}=0.368 \pm\right.$ $0.010 ; p=0.05)$, Ct.Th $((\mathrm{mm}): \mathrm{ERKO}=0.247 \pm 0.003 ; \mathrm{WT}=0.257 \pm 0.003 ; p=0.02)$, and robustness ((no unit): $\mathrm{ERKO}=0.55 \pm 0.01 ; \mathrm{WT}=0.59 \pm 0.01 ; p=0.01)$. There was a significant main effect of EX on Ct.Ar $\left(\left(\mathrm{mm}^{2}\right): \mathrm{Ex}=0.691 \pm 0.011 ; \mathrm{Sed}=0.646 \pm 0.011 ; p=0.02\right)$ and Ct.Th $((\mathrm{mm}): \mathrm{Ex}=0.258 \pm$ $0.003 ;$ Sed $=0.247 \pm 0.003 ; p=0.03)$.

\subsection{Tibial Biomechanical Strength}

Exercising animals had significantly lower Young's modulus of elasticity than their sedentary counterparts $(p=0.04)$, regardless of genotype. There were no differences between groups in max force, stiffness, work-to-fracture, or modulus of toughness (Figure 2). 
When body weight was not used as a covariate, there were no differences between groups in any biomechanical outcomes (data not shown).
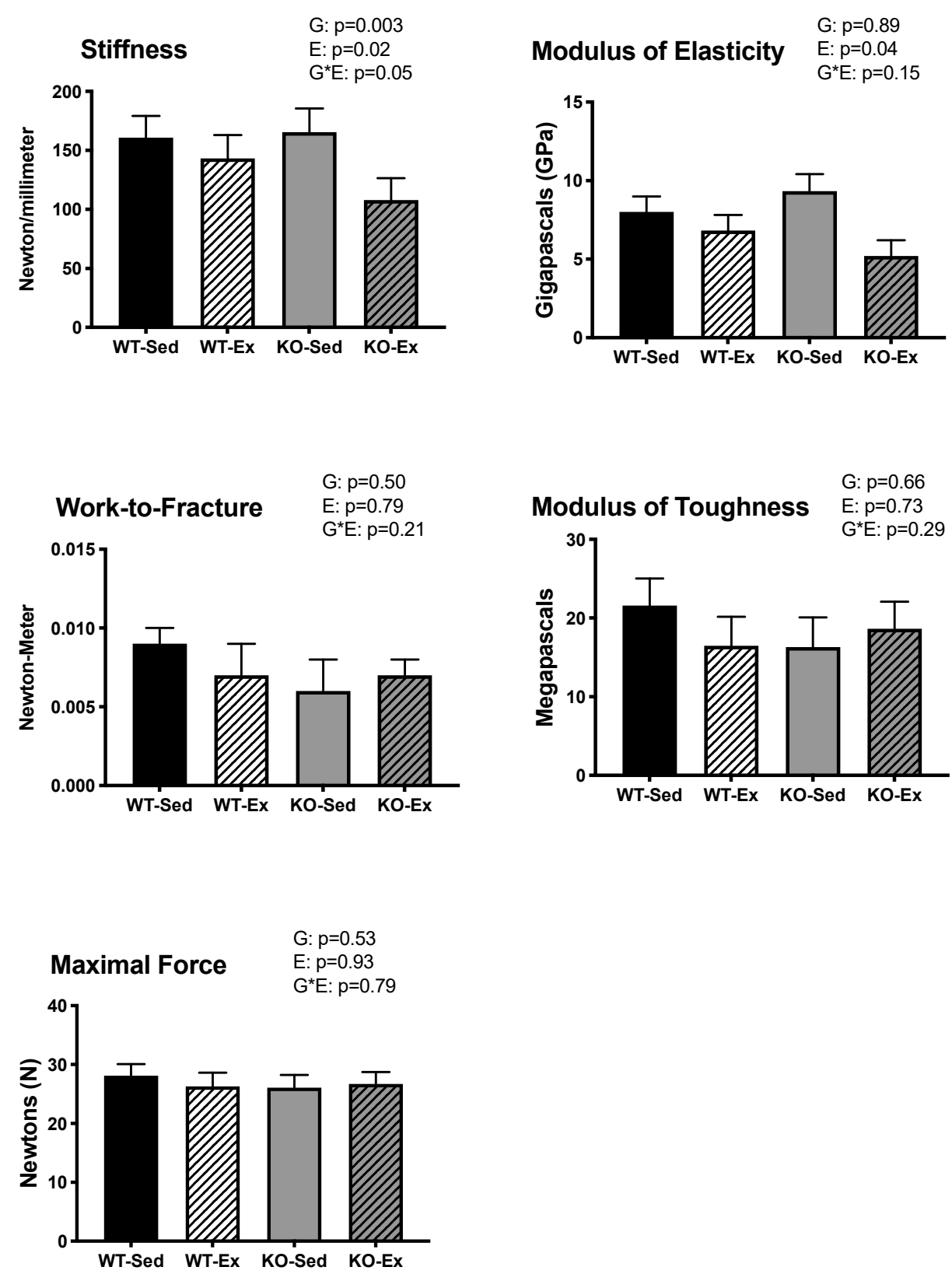

Figure 2. Biomechanical properties. Biomechanical strength of the tibia. Data are adjusted means \pm SEM, $n=6-8$ per group ERKO: ER $\alpha$ knock out; WT: wild type; Ex: voluntary wheel running; Sed: sedentary. G: main effect of genotype $(p \leq 0.05)$; EX: main effect of exercise status $(p \leq 0.05)$. There was a significant main effect of EX on Young's modulus of elasticity ((GPa): $\mathrm{Ex}=6.012 \pm 0.762 ;$ Sed $=8.665 \pm 0.762 ; p=0.04)$.

\subsection{Tibial Trabecular Microarchitecture}

There was a main effect of genotype on BV/TV ( $p=0.034)$, Tb.N $(p=0.001)$, Conn.D $(p=0.001)$, and SMI $(p=0.04)$, with ERKO animals having higher values than WT animals in these outcomes. There was a main effect of genotype on Tb.Th $(p=0.006)$ and $\mathrm{Tb} . \mathrm{Sp}$ $(p=0.001)$, with ERKO animals having lower values than WT animals. Exercising animals had significantly higher DA than their sedentary counterparts $(p=0.01)$, regardless of genotype (Figure 3). 

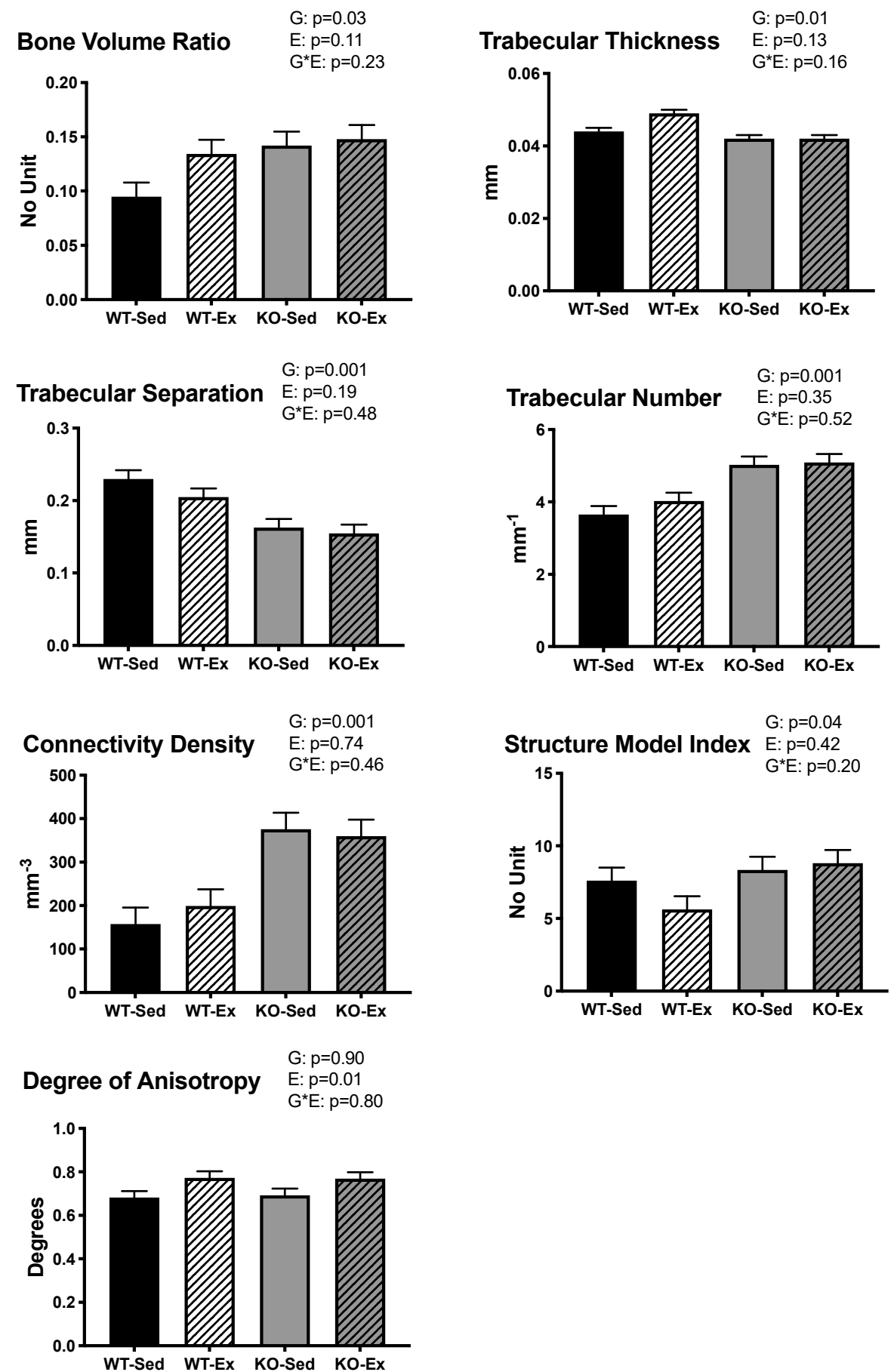

Figure 3. Tibial trabecular microarchitecture. Trabecular microarchitecture of the tibia. Data are means \pm SEM, $n=6-8$ per group ERKO: ER $\alpha$ knock out; WT: wild type; Ex: voluntary wheel running; Sed: sedentary. G: main effect of genotype $(p \leq 0.05)$; EX: main effect of exercise status $(p \leq 0.05)$. There was a significant main effect of $\mathrm{G}$ on BV/TV ((no unit): ERKO $=0.145 \pm 0.01$; $\mathrm{WT}=0.114 \pm 0.01 ; p=0.03)$, Tb.Th $((\mathrm{mm}): \mathrm{ERKO}=0.042 \pm 0.001 ; \mathrm{WT}=0.047 \pm 0.001 ; p=0.006), \mathrm{Tb} . \mathrm{Sp}$ $((\mathrm{mm}): \mathrm{ERKO}=0.159 \pm 0.01 ; \mathrm{WT}=0.218 \pm 0.01 ; p=0.001), \mathrm{Tb} . \mathrm{N}\left(\left(\mathrm{mm}^{-1}\right): \mathrm{ERKO}=5.06 \pm 0.163 ;\right.$ $\mathrm{WT}=3.84 \pm 0.16 ; p=0.001)$, Conn.D $\left(\left(\mathrm{mm}^{3}\right):\right.$ ERKO = 367.7 $\left.\pm 26.9 ; \mathrm{WT}=178.5 \pm 26.9 ; p=0.001\right)$, and SMI ((no unit): ERKO = 8.58 $\pm 0.64 ; \mathrm{WT}=6.62 \pm 0.64 ; p=0.04)$. There was a significant main effect of EX on DA ((degree): Ex $=0.771 \pm 0.021$; Sed $=0.688 \pm 0.021 ; p=0.01$ ). 


\subsection{Femoral Osteocyte Sclerostin Expression}

There were no differences in percent empty lacunae or percent sclerostin-positive osteocytes between groups in samples of either cortical or cancellous bone (Figure 4).

\section{Cortical Bone}

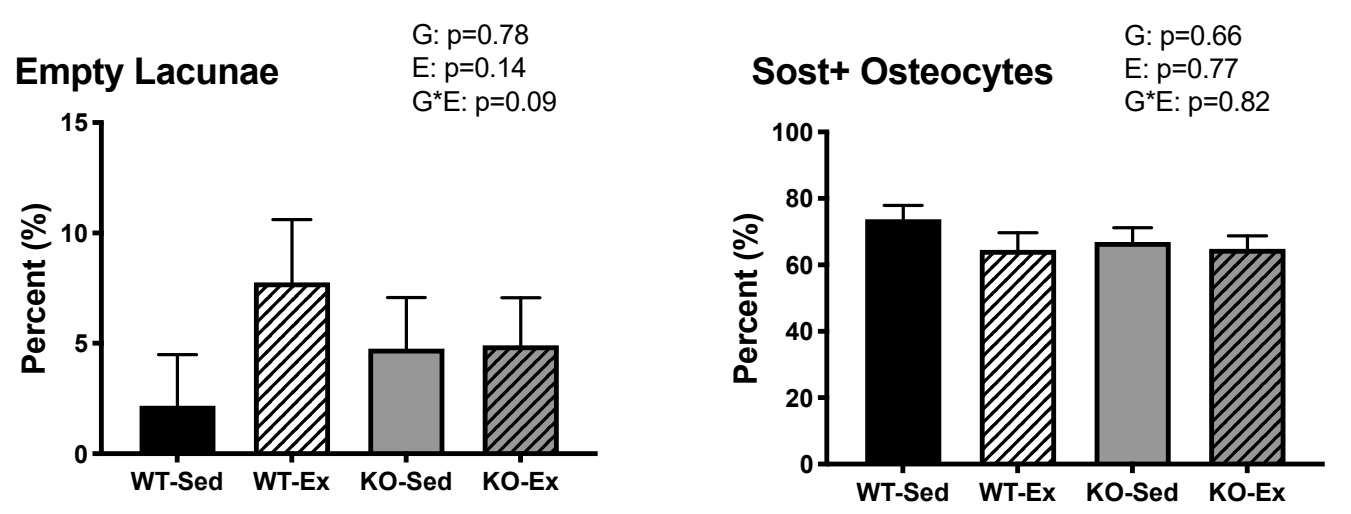

Cancellous Bone
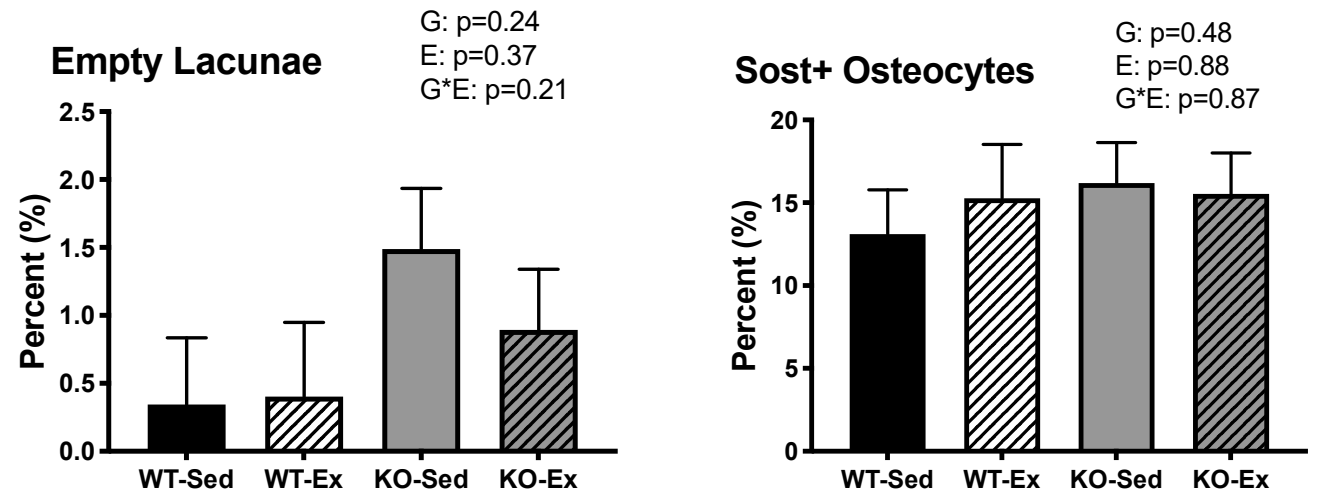

Figure 4. Sclerostin expression. Sclerostin expression of the femur in cortical and cancellous bone. Data are means $\pm \mathrm{SEM}$, $n=6-8$ per group ERKO: ER $\alpha$ knock out; WT: wild type; Ex: voluntary wheel running; Sed: sedentary.

\section{Discussion}

Here we showed that ERKO had differential effects on cortical and cancellous bone in young male mice compared to their WT counterparts. More specifically, ERKO animals, regardless of exercise status, had improved measures of trabecular microarchitecture, such as bone volume and trabecular number; however sedentary ERKO animals had significant negative alterations in cortical bone geometry, such as reduced cortical thickness and area relative to controls. We also found that exercise begun after skeletal maturity could reverse some of these negative alterations in cortical bone of ERKO mice. Exercising male ERKO animals had significantly improved measures of cortical geometry than their sedentary counterparts, implying that ER $\alpha$ is not necessary for males to grow bone in response to exercise. Exercise, regardless of genotype, decreased Young's modulus of elasticity in the tibia, but there was no effect of exercise or genotype on any other measures of biomechanical strength or sclerostin expression in cortical or cancellous bone of the femur.

The negative morphological changes seen in the cortical bone of male, global ERKO animals in this study are supported by previous studies both by ourselves [35] and others [9-11]. Estrogen and estrogen receptors have significant, cell-specific roles in the development and maintenance of bone mass-estrogen blocks osteocyte and osteoblast apoptosis, induces osteoblast differentiation, increases osteoclast apoptosis, and reduces osteoclast differentiation [36-40]. ER $\alpha$ is particularly important in the maintenance of cortical bone mass due to its higher prevalence compared to ER $\beta$ [6] and its actions in certain cell types. When ER $\alpha$ was deleted from osteoblast precursors, femoral BMD and 
cortical thickness were reduced compared to wild-type animals [41], whereas there were no alterations in cortical bone when ER $\alpha$ was deleted from mature osteocytes only [42]. This indicates that $\mathrm{ER} \alpha$ controls cortical bone formation through actions on progenitor cells and supports our findings in this global knockout model.

Previous studies have shown that both global [19] and osteoblast-specific [20] male ERKO models can respond to exercise despite the loss of ER $\alpha$. This is in direct contrast to females, which require ER $\alpha$ for an osteogenic response to exercise [18]. To the authors' knowledge, we were the first to further explore one cellular mechanism of the exercise response by analyzing sclerostin expression in male ERKO animals. We have previously shown that aged, sedentary male ERKO animals have higher sclerostin expression than their WT counterparts [35]. Considering that exercise downregulates sclerostin [24], we wanted to explore whether exercise-induced decreases in sclerostin are estrogen-mediated. While exercise decreased sclerostin expression in both groups, it was not statistically significant. There were no differences between ERKO and WT in sclerostin expression, which implies that there is no effect of ERKO on sclerostin expression in younger males. The differences between this study and our previous study [35] could be partially explained by age or metabolic status. In our previous study, ERKO animals had higher fasting blood glucose levels than their WT counterparts, and high blood glucose is associated with increased sclerostin expression [24]. In this study, there were no difference in blood glucose, which could partially explain the lack of differences in sclerostin expression. In addition, sclerostin naturally increases with age [24], and this higher expression overall could exacerbate differences triggered by metabolic changes over time. However, more studies are needed to fully understand the interaction of $\mathrm{ER} \alpha$, age, and exercise on sclerostin expression.

Exercise had minimal effects in the cortical bone of WT animals. Exercise increased cortical thickness but did not have a significant effect on measures of area or robustness. We attribute this to the initiation of exercise after skeletal maturity-exercise began at 12 weeks of age, which is around skeletal maturity [43]. Previous studies have shown that bone cells are less responsive to exercise after skeletal maturity, and it thus takes higher mechanical forces to induce osteogenesis [44]. However, in the ERKO animals, which had significant impairments in cortical bone geometry, exercise induced enough strain for a significant osteogenic response. This could partially be due to the increased body weight in exercising ERKO animals compared to exercising WT animals, since higher body weight would result in higher strains [45]. This also could be an indicator that ER $\alpha$ limits the sensitivity of bone to exercise, and the removal of ER $\alpha$ allows for a more robust osteogenic response. Exercising ERKO animals had significantly higher cortical and total area, cortical thickness, and robustness than their sedentary counterparts, which equalized their cortical geometry to that of the WT animals. Interestingly, exercising animals had lower Young's modulus of elasticity and stiffness, although stiffness was not quite at a significant level $(p=0.10)$, regardless of genotype. Both are measures of the elasticity of the bone, or the ability of the bone to resist deformation before fracture, but stiffness is a measure of the elasticity of the bone structure whereas Young's modulus is a measure of the elasticity of the bone material. There was no effect of exercise or genotype on maximal load sustained, suggesting that these alterations in stiffness and elasticity did not have a negative impact on overall strength of the bone. The differences in Young's modulus without corresponding differences in cortical geometry could indicate differences in bone quality. While we saw no differences in voxel intensity, a proxy measure for tissue mineral density, this difference in Young's modulus would warrant further exploration of tissue-level measures of bone quality in the future. It should also be acknowledged that tibiae have an irregular crosssectional shape, which makes them less suitable for a three-point bending test than a tubular bone, such as the radius or femur [46], and this higher variability in results could contribute to the lack of statistical differences.

The positive morphological changes in the trabecular bone of the ERKO animals have also been supported in previous studies by both ourselves [35] and others [10,11]. These improvements can be explained by the greater presence of ER $\beta$ in cancellous bone. 
In cancellous bone, ER $\beta$ and ER $\alpha$ appear to have similar actions, and both play a role in maintaining total bone mass [40]. Thus, the loss of ER $\alpha$ does not lead to a loss of bone mass as it does in cortical bone. In fact, our results could indicate that ER $\alpha$ plays a more regulatory or restrictive role in trabecular bone, considering that the loss of ER $\alpha$ increases measures of trabecular bone mass. However, we were one of the first to explore the effects of exercise on trabecular microarchitecture in ERKO mice, as well as further explore the cellular mechanisms by measuring sclerostin expression. Exercise begun after skeletal maturity increased the degree of anisotropy, which is a strong indicator of trabecular bone strength [47]. Thus, it is possible that exercise increased the strength of the trabecular bone in conjunction with the morphological changes; however, we did not have the capacity to measure trabecular bone strength. We saw no effect of ERKO or exercise on sclerostin expression in cancellous bone, consistent with previous studies [35].

In conclusion, we found that ERKO has differential effects on cortical and cancellous bone in young, male mice. Specifically, ERKO significantly improved trabecular microarchitecture, implying ER $\alpha$ is not required for the maintenance of trabecular bone. However, ERKO negatively impacted cortical geometry, which supports a significant role for ER $\alpha$ in the maintenance of cortical bone in sedentary animals. We also found that exercise started after skeletal maturity was able to reverse the negative alterations in cortical geometry in the ERKO animals. This would indicate that ER $\alpha$ is not necessary for an osteogenic response to mechanical loading in male mice. There were no effects of ERKO or exercise on sclerostin expression, and thus further studies are warranted to explore additional cellular mechanisms which allow this osteogenic response to exercise in male ERKO animals and if these mechanisms can translate to humans. This would allow for further understandings of potential targets to improve the efficacy of exercise treatments for osteoporosis and other diseases of low bone mass in both men and women.

\section{Materials and Methods}

\subsection{Experimental Design}

This study is part of a larger study investigating the effects of global ERKO on glycemic control, inflammation, and hepatic steatosis in male mice, and whether exercise could be an effective treatment to reverse the negative impacts of ERKO [34]. Heterozygote ER $\alpha-/+$ mice on a C57BL/6J background were bred at our facility to produce male homozygote (ER $\alpha-/-)$ and littermate wild-type mice, as previously described [48,49]. Briefly, development of the ER $\alpha-/$ - mouse was accomplished by homologous recombination and insertion of a neomycin sequence containing premature stop codons and polyadenylation sequences into a Not1site in exon 2 of the mouse estrogen receptor gene [48-50]. After weaning, mice were fed standard rodent chow ((3.3 kcal $/ \mathrm{g}$ of food), $13 \% \mathrm{kcal} \mathrm{fat,}$ $57 \% \mathrm{kcal}$ carbohydrate, and 30\% kcal protein, 5001, LabDiet, St. Louis, MO, USA) ad libitum until 12 weeks of age. At 12 weeks of age, all mice were given ad libitum access to a high-fat diet (4.65 kcal/g of food; $46.0 \%$ kcals from fat, $36.0 \% \mathrm{kcals}$ from carbohydrate with sucrose content (per weight) of $17.5 \%$ and high-fructose corn syrup content of $17.5 \%$ (Test Diet modified 58Y1; 5APC)), and both ER $\alpha-/-(E R K O)$ and wild-type (WT) animals were randomized into two groups-an exercising (EX) group given access to running wheels, and a sedentary (SED) control group with no running wheels-resulting in four experimental groups: ERKO-EX, ERKO-SED, WT-EX, and WT-SED ( $n=6-8$ /group). All mice were pair-housed (mixed genotypes) in a temperature-controlled environment at $25^{\circ} \mathrm{C}$, with a 0700-1900 light, 1900-0700 dark cycle. Body weight and food intake were measured weekly, and body composition was measured by a nuclear magnetic resonance imaging whole-body composition analyzer (EchoMRI 4in1/1100; Echo Medical Systems, Houston, TX, USA) on conscious mice one week prior to sacrifice. At 22 weeks of age, mice were euthanized following a $5 \mathrm{~h}$ fast. Blood samples were collected via cardiac puncture and centrifuged; plasma was separated, frozen in liquid nitrogen, and stored at $-80{ }^{\circ} \mathrm{C}$ for further analysis. Circulating estradiol and fasting insulin, glucose, and lipids were measured as previously described [34]. Hindlimbs were harvested, wrapped in PBS-soaked 
gauze, frozen in liquid nitrogen, and stored at $-80{ }^{\circ} \mathrm{C}$ for further analysis. All procedures were approved in advance by the University of Missouri Institutional Animal Care and Use Committee.

\subsection{Tibial Cortical Geometry and Trabecular Microarchitecture}

Micro-computed tomographic $(\mu \mathrm{CT})$ imaging of the right tibia was performed using a high-resolution imaging system (Xradia 520 Versa, ZEISS, Oberkochen, Germany). The methods used were in accordance with guidelines for the use of $\mu \mathrm{CT}$ in rodents [51]. Scans were acquired using an isotropic voxel size of $0.012 \mathrm{~mm}$, a peak X-ray tube potential of $60 \mathrm{kV}$, and $2 \mathrm{~s}$ exposure time. Trabecular bone microarchitecture was evaluated in a $0.5 \mathrm{~mm}$ region of interest directly below the growth plate of the proximal tibia, as previously described [52,53]. Cortical bone cross-sectional geometry was evaluated at a $1 \mathrm{~mm}$ region of interest at the mid-diaphysis of the tibia, or the midway point between the tibial crest and the tibiofibular joint, as previously described [52,53]. The optimized threshold function was used to delineate mineralized bone from soft tissue. Scans were analyzed using BoneJ software [54] (NIH public domain), and measures of cortical geometry and trabecular microarchitecture were collected. Outcomes for cortical geometry included tibia length (Le), total cross-sectional area inside the periosteal envelope (Tt.Ar), marrow area (Ma.Ar), cortical bone area (Ct.Ar), cortical area fraction (Ct.Ar/Tt.Ar), mean cortical thickness (Ct.Th), and robustness ( $\mathrm{R}$, total bone area over length calculated as $\mathrm{R}=\mathrm{Tt}$.Ar/Le). Voxel gray-scale intensity of the cortical bone was measured as a proxy for tissue mineral density. Outcomes for trabecular microarchitecture included bone volume fraction (BV/TV), connectivity density (Conn.D, degree of trabeculae connectivity normalized to total bone volume), mean trabecular thickness (Tb.Th), trabecular separation ( $\mathrm{Tb} . \mathrm{Sp}$, distance between trabeculae), trabecular number ( $\mathrm{Tb} . \mathrm{N}$, average number of trabeculae per unit length calculated as 1/(Tb.Th + Tb.Sp) [55]), structural model index (SMI), and degree of anisotropy (DA).

\subsection{Tibial Biomechanical Strength}

Biomechanical strength of the right tibia was performed using three-point bending [56]. Briefly, tibias were cleaned of all soft tissue and placed in the three-point bending apparatus with a span of $6 \mathrm{~mm}$. Tibiae were loaded via a materials testing machine (Instron 5942; Instron, Inc., Norwood, MA, USA) at a rate of $10 \mathrm{~mm} /$ minute at the midpoint of the tibia until fracture. Outputs from the Instron machine were used to produce a load-displacement curve. The slope of the load-displacement curve was used to estimate material stiffness, and the area under the load-displacement curve was used to estimate work-to-fracture [57]. Maximal load was measured as the highest force applied to the bone before fracture [57]. Load-displacement data were converted into stress and strain to produce a stress-strain curve using the geometric measurements of the bone and following the equations of Turner and Burr [57]. The slope of the stress-strain curve was used to estimate Young's modulus of elasticity, and the area under the curve was used to estimate the modulus of toughness [57].

\subsection{Femoral Osteocyte Sclerostin Expression}

The right femurs were fixed in $10 \%$ formalin for $48 \mathrm{~h}$ at $4{ }^{\circ} \mathrm{C}$ and then decalcified in $14 \%$ EDTA at $4{ }^{\circ} \mathrm{C}$. Decalcified femurs were embedded in paraffin wax blocks, and $5 \mu \mathrm{m}$ sections were taken transversely at the mid-diaphysis and the proximal metaphysis above the growth place of the femur, for measures of cortical and cancellous bone, respectively. The sections were deparaffinized and underwent heat-induced epitope retrieval overnight at $60{ }^{\circ} \mathrm{C}$ using a $10 \mathrm{mM}$ sodium citrate buffer, followed by blocking of endogenous avidin and biotin expression (Avidin Biotin Blocking Solution, Thermo Scientific, Waltham, MA, USA). Sections were then incubated in anti-sclerostin primary antibodies (Abcam, Cambridge, UK) overnight at $4{ }^{\circ} \mathrm{C}$, followed by blocking of endogenous peroxidase activity $\left(3 \% \mathrm{H}_{2} \mathrm{O}_{2}\right.$, Ricca Chemical, Arlington, TX, USA) and secondary antibody application. Secondary antibody binding and detection were accomplished using 
a Vectastain Elite $A B C$ kit (Vector Laboratories, Burlingame, CA, USA), with diaminobenzidine (ImmPACT DAB, Vector Laboratories, Burlingame, CA, USA) as the chromogen. Sections were counterstained with hematoxylin (Fisher Scientific, Hampton, NH, USA), dried, and mounted. Sections were analyzed at $20 \times$ for sclerostin expression. Sclerostin positive (Sost + ) osteocytes were defined as osteocytes exhibiting brown staining, and sclerostin negative (Sost-) osteocytes were defined as osteocytes exhibiting blue (hematoxylin) staining. Data are reported as percent Sost+ osteocytes. In addition to Sost+ and Sostosteocytes, empty osteocytic lacunae revealed by hematoxylin staining were counted, and data are reported as percent empty lacunae, as previously described [58].

\subsection{Statistical Analysis}

Two-way ANOVA was used to assess the main and interactive effects of genotype and exercise on metabolic outcomes, trabecular microarchitecture, and percentage of sclerostin+ osteocytes. Body weight is a strong predictor of cortical bone size and strength, so cortical geometry and biomechanical strength outcomes were assessed by two-way ANCOVA with final body weight included as a covariate [56]. We also ran two-way ANOVAs on cortical outcomes to confirm that differences body weight were a main driver in cortical differences. If an interaction was present, one-way ANOVA or ANCOVA was used as necessary to determine the location of the interaction. Data are presented as means \pm SEM or adjusted means \pm SEM. Statistical significance was set at $p<0.05$. All analyses were performed using SPSS software (SPSS /25.0, SPSS, Chicago, IL, USA).

Author Contributions: Conceptualization, J.P., V.J.V.-P. and P.S.H.; methodology, J.P., V.J.V.-P., P.S.H.; validation, R.K.D. and P.S.H.; formal Analysis, R.K.D. and N.C.W.; investigation, R.K.D., N.C.W. and T.J.J.; resources, D.B.L.; data curation, R.K.D., N.C.W. and T.J.J.; writing—original draft preparation, R.K.D.; writing - review and editing, R.K.D., P.S.H.; visualization, R.K.D. and N.C.W.; supervision, P.S.H.; project administration, J.P. and P.S.H.; funding acquisition, J.P., N.C.W. All authors have read and agreed to the published version of the manuscript.

Funding: This study was supported in part by grants from National Institutes of Health (NIH) K01 HL-125503 (to J.P.) and American Egg Board \#00050021 (to N.C.W.).

Institutional Review Board Statement: The study was conducted according to the guidelines of the Animal Care and Use Committee at the University of Missouri.

Informed Consent Statement: Not Applicable.

Data Availability Statement: Data available upon request.

Acknowledgments: We greatly acknowledge the technical assistance of Michelle Gastecki, Gabriela Lin, and Kevin Middleton. We also thank the University of Missouri (MU) Veterinary Medicine Diagnostic Laboratory (VMDL) and the MU X-ray Microanalysis Core (Mizzo $\mu X)$ for their technical assistance.

Conflicts of Interest: The authors declare no conflict of interests.

\section{References}

1. Cutler, G.B. The Role of Estrogen in Bone Growth and Maturation during Childhood and Adolescence. J. Steroid Biochem. Mol. Biol. 1997, 616, 141-144. [CrossRef]

2. $\quad$ Fortes, C.M.T.; Goldberg, T.B.L.; Kurokawa, C.S.; Silva, C.C.; Moretto, M.R.; Biason, T.P.; Teixeira, A.S.; De Carvalho Nunes, H.R. Relationship between chronological and bone ages and pubertal stage of breasts with bone biomarkers and bone mineral density in adolescents. J. Pediatr. (Rio. J.) 2014, 90, 624-631. [CrossRef]

3. Yilmaz, D.; Ersoy, B.; Bilgin, E.; Gümüşer, G.; Onur, E.; Pinar, E.D. Bone mineral density in girls and boys at different pubertal stages: Relation with gonadal steroids, bone formation markers, and growth parameters. J. Bone Miner. Metab. 2005, $23,476-482$. [CrossRef]

4. Khosla, S.; Melton, L.J.; Riggs, B.L. Estrogens and Bone Health in Men. Calcif. Tissue Int. 2001, 69, 189-192. [CrossRef]

5. Cauley, J.A. Estrogen and bone health in men and women. Steroids 2015, 99, 11-15. [CrossRef] [PubMed]

6. Onoe, Y.; Miyaura, C.; Ohta, H.; Nozawa, S.; Suda, T. Expression of Estrogen Receptor $\beta$ in Rat Bone. Endocrinology 1997, 138, 4509-4512. [CrossRef] [PubMed] 
7. Parikka, V.; Peng, Z.; Hentunen, T.; Risteli, J.; Elo, T.; Väänänen, H.K.; Härkönen, P. Estrogen responsiveness of bone formation in vitro and altered bone phenotype in aged estrogen receptor-a-deficient male and female mice. Eur. J. Endocrinol. 2005, 152, 301-314. [CrossRef] [PubMed]

8. Vandenput, L.; Ederveen, A.G.H.; Erben, R.G.; Stahr, K.; Swinnen, J.V.; Van Herck, E.; Verstuyf, A.; Boonen, S.; Bouillon, R.; Vanderschueren, D. Testosterone Prevents Orchidectomy-Induced Bone Loss in Estrogen Receptor- $\alpha$ Knockout Mice. Biochem. Biophys. Res. Commun. 2001, 285, 70-76. [CrossRef]

9. Vidal, O.; Lindberg, M.K.; Hollberg, K.; Baylink, D.J.; Andersson, G.; Lubahn, D.B.; Mohan, S.; Gustafsson, J.A.; Ohlsson, C. Estrogen receptor specificity in the regulation of skeletal growth and maturation in male mice. Proc. Natl. Acad. Sci. USA 2000, 97, 5474-5479. [CrossRef]

10. Callewaert, F.; Venken, K.; Ophoff, J.; De Gendt, K.; Torcasio, A.; van Lenthe, G.H.; Van Oosterwyck, H.; Boonen, S.; Bouillon, R.; Verhoeven, G.; et al. Differential regulation of bone and body composition in male mice with combined inactivation of androgen and estrogen receptor-alpha. FASEB J. 2009, 23, 232-240. [CrossRef]

11. Lindberg, M.K.; Erlandsson, M.; Alatalo, S.L.; Windahl, S.; Andersson, G.; Halleen, J.M.; Carlsten, H.; Gustafsson, J.A.; Ohlsson, C. Estrogen receptor alpha, but not estrogen receptor beta, is involved in the regulation of the OPG/RANKL (osteoprotegerin/receptor activator of NF-kappa B ligand) ratio and serum interleukin-6 in male mice. J. Endocrinol. 2001, 171, 425-433. [CrossRef]

12. Galea, G.L.; Price, J.S.; Lanyon, L.E. Estrogen receptors' roles in the control of mechanically adaptive bone (re)modeling. Bonekey Rep. 2013, 2. [CrossRef]

13. Klein-Nulend, J.; Van Oers, R.F.M.; Bakker, A.D.; Bacabac, R.G. Bone cell mechanosensitivity, estrogen deficiency, and osteoporosis. J. Biomech. 2015, 48, 855-865. [CrossRef] [PubMed]

14. Galea, G.L.; Meakin, L.B.; Sugiyama, T.; Zebda, N.; Sunters, A.; Taipaleenmaki, H.; Stein, G.S.; Van Wijnen, A.J.; Lanyon, L.E.; Price, J.S. Estrogen receptor $\alpha$ mediates proliferation of osteoblastic cells stimulated by estrogen and mechanical strain, but their acute down-regulation of the Wnt antagonist Sost is mediated by estrogen receptor $\beta$. J. Biol. Chem. 2013, 288, 9035-9048. [CrossRef] [PubMed]

15. Armstrong, V.J.; Muzylak, M.; Sunters, A.; Zaman, G.; Saxon, L.K.; Price, J.S.; Lanyon, L.E. Wnt/Beta-Catenin Signaling Is a Component of Osteoblastic Bone Cell Early Responses to Load-bearing and Requires Estrogen Receptor-alpha. J. Biol. Chem. 2007, 282, 20715-20727. [CrossRef] [PubMed]

16. Jessop, H.L.; Sjöberg, M.; Cheng, M.Z.; Zaman, G.; Wheeler-Jones, C.P.D.; Lanyon, L.E. Mechanical Strain and Estrogen Activate Estrogen Receptor $\alpha$ in Bone Cells. J. Bone Miner. Res. 2001, 16, 1045-1055. [CrossRef]

17. Okazaki, R.; Inoue, D.; Shibata, M.; Saika, M.; Kido, S.; Ooka, H.; Tomiyama, H.; Sakamoto, Y.; Matsumoto, T. Estrogen Promotes Early Osteoblast Differentiation and Inhibits Adipocyte Differentiation in Mouse Bone Marrow Stromal Cell Lines that Express Estrogen Receptor (ER) $\alpha$ or $\beta$. Endocrinology 2002, 143, 2349-2356. [CrossRef]

18. Windahl, S.H.; Saxon, L.; Börjesson, A.E.; Lagerquist, M.K.; Frenkel, B.; Henning, P.; Lerner, U.H.; Galea, G.L.; Meakin, L.B.; Engdahl, C.; et al. Estrogen receptor- $\alpha$ is required for the osteogenic response to mechanical loading in a ligand-independent manner involving its activation function 1 but not 2. J. Bone Miner. Res. 2013, 28, 291-301. [CrossRef]

19. Saxon, L.K.; Galea, G.; Meakin, L.; Price, J.; Lanyon, L.E. Estrogen Receptors Alpha and Beta Have Different Gender-Dependent Effects on the Adaptive Responses to Load Bearing in Cancellous and Cortical Bone. Endocrinology 2012, 153, $2254-2266$. [CrossRef]

20. Melville, K.M.; Kelly, N.H.; Surita, G.; Buchalter, D.B.; Schimenti, J.C.; Main, R.P.; Ross, F.P.; van der Meulen, M.C. Effects of Deletion of $\mathrm{ER} \alpha$ in Osteoblast-Lineage Cells on Bone Mass and Adaptation to Mechanical Loading Differ in Female and Male Mice. J. Bone Miner. Res. 2015, 30, 1468-1480. [CrossRef]

21. Callewaert, F.; Sinnesael, M.; Gielen, E.; Boonen, S.; Vanderschueren, D. Skeletal sexual dimorphism: Relative contribution of sex steroids, GH-IGF1, and mechanical loading. J. Endocrinol. 2010, 207, 127-134. [CrossRef]

22. Lerner, U.H.; Ohlsson, C. The WNT system: Background and its role in bone. J. Intern. Med. 2015, 277, 630-649. [CrossRef] [PubMed]

23. Burgers, T.A.; Williams, B.O.; Bonewald, L.F.; Johnson, M.E.; Kneissel, M. Regulation of Wnt/ $\beta$-catenin signaling within and from osteocytes. Bone 2013, 54, 244-249. [CrossRef] [PubMed]

24. Delgado-Calle, J.; Sato, A.Y.; Bellido, T. Role and mechanism of action of sclerostin in bone. Bone 2017, 96, 29-37. [CrossRef] [PubMed]

25. Galea, G.L.; Lanyon, L.E.; Price, J.S. Sclerostin's role in bone's adaptive response to mechanical loading. Bone 2017, 9. [CrossRef] [PubMed]

26. Mödder, U.I.; Hoey, K.A.; Amin, S.; McCready, L.K.; Achenbach, S.J.; Riggs, B.L.; Melton, L.J.; Khosla, S. Relation of age, gender, and bone mass to circulating sclerostin levels in women and men. J. Bone Miner. Res. 2011, 26, 373-379. [CrossRef]

27. Kim, W.; Chung, Y.; Kim, S.H.; Park, S.; Bae, J.H.; Kim, G.; Lee, S.J.; Kim, J.E.; Park, B.-W.; Lim, S.-K.; et al. Increased Sclerostin Levels after Further Ablation of Remnant Estrogen by Aromatase Inhibitors. Endocrinol. Metab. 2015, 30, 58-64. [CrossRef]

28. Mirza, F.S.; Padhi, I.D.; Raisz, L.G.; Lorenzo, J.A. Serum Sclerostin Levels Negatively Correlate with Parathyroid Hormone Levels and Free Estrogen Index in Postmenopausal Women. J. Clin. Endocrinol. Metab. 2010, 95, 1991-1997. [CrossRef] 
29. Fujita, K.; Roforth, M.M.; Demaray, S.; Mcgregor, U.; Kirmani, S.; Mccready, L.K.; Peterson, J.M.; Drake, M.T.; Monroe, D.G.; Khosla, S. Effects of Estrogen on Bone mRNA Levels of Sclerostin and Other Genes Relevant to Bone Metabolism in Postmenopausal Women. J. Clin. Endocrinol. Metab. 2014, 99, E81-E88. [CrossRef]

30. Kim, B.-J.; Bae, S.J.; Lee, S.-Y.; Lee, Y.-S.; Baek, J.-E.; Park, S.-Y.; Lee, S.H.; Koh, J.-M.; Kim, G.S. TNF-alpha mediates the stimulation of sclerostin expression in an estrogen-deficient condition. Biochem. Biophys. Res. Commun. 2012, 424, 170-175. [CrossRef]

31. Jia, H.B.; Ma, J.X.; Ma, X.L.; Yu, J.T.; Feng, R.; Xu, L.Y.; Wang, J.; Xing, D.; Zhu, S.W.; Wang, Y. Estrogen alone or in combination with parathyroid hormone can decrease vertebral MEF2 and sclerostin expression and increase vertebral bone mass in ovariectomized rats. Osteoporos. Int. 2014, 25, 2743-2754. [CrossRef] [PubMed]

32. Mödder, U.I.L.; Clowes, J.A.; Hoey, K.; Peterson, J.M.; McCready, L.; Oursler, M.J.; Riggs, B.L.; Khosla, S. Regulation of circulating sclerostin levels by sex steroids in women and in men. J. Bone Miner. Res. 2011, 26, 27-34. [CrossRef]

33. Delgado-Calle, J.; Sañudo, C.; Bolado, A.; Fernández, A.F.; Arozamena, J.; Pascual-Carra, M.A.; Rodriguez-Rey, J.C.; Fraga, M.F.; Bonewald, L.; Riancho, J.A. DNA methylation contributes to the regulation of sclerostin expression in human osteocytes. J. Bone Miner. Res. 2012, 27, 926-937. [CrossRef] [PubMed]

34. Winn, N.C.; Jurrissen, T.J.; Grunewald, Z.I.; Cunningham, R.P.; Woodford, M.L.; Kanaley, J.A.; Lubahn, D.B.; Manrique-Acevedo, C.; Rector, R.S.; Vieira-Potter, V.J.; et al. Estrogen receptor alpha signaling maintains immunometabolic function in males and is obligatory for exercise-induced amelioration of nonalcoholic fatty liver. Am. J. Physiol. Metab. 2018, 16, E156-E167. [CrossRef]

35. Dirkes, R.K.; Winn, N.C.; Jurrissen, T.J.; Lubahn, D.B.; Vieira-Potter, V.J.; Padilla, J.; Hinton, P.S. Global estrogen receptor- $\alpha$ knockout has differential effects on cortical and cancellous bone in aged male mice. FACETS 2020, 5, 328-348. [CrossRef]

36. Khosla, S.; Oursler, M.J.; Monroe, D.G. Estrogen and the skeleton. Trends Endocrinol. Metab. 2012, 23, 576-581. [CrossRef]

37. Syed, F.; Khosla, S. Mechanisms of sex steroid effects on bone. Biochem. Biophys. Res. Commun. 2005, 328, 688-696. [CrossRef]

38. Shevde, N.K.; Bendixen, A.C.; Dienger, K.M.; Pike, J.W.; Deluca, H.F. Estrogens suppress RANK ligand-induced osteoclast differentiation via a stromal cell independent mechanism involving c-Jun repression. Proc. Natl. Acad. Sci. USA 2000, 97, 7829-7834. [CrossRef]

39. Bord, S.; Ireland, D.; Beavan, S.; Compston, J. The effects of estrogen on osteoprotegerin, RANKL, and estrogen receptor expression in human osteoblasts. Bone 2003, 32, 136-141. [CrossRef]

40. Khalid, A.B.; Krum, S.A. Estrogen receptors alpha and beta in bone. Bone 2016, 87, 130-135. [CrossRef]

41. Almeida, M.; Iyer, S.; Martin-Millan, M.; Bartell, S.M.; Han, L.; Ambrogini, E.; Onal, M.; Xiong, J.; Weinstein, R.S.; Jilka, R.L.; et al. Estrogen receptor- $\alpha$ signaling in osteoblast progenitors stimulates cortical bone accrual. J. Clin. Investig. 2013, 123, 394-404. [CrossRef] [PubMed]

42. Windahl, S.H.; Börjesson, A.E.; Farman, H.H.; Engdahl, C.; Movérare-Skrtic, S.; Sjögren, K.; Lagerquist, M.K.; Kindblom, J.M.; Koskela, A.; Tuukkanen, J.; et al. Estrogen receptor- $\alpha$ in osteocytes is important for trabecular bone formation in male mice. Proc. Natl. Acad. Sci. USA 2013, 110, 2294-2299. [CrossRef] [PubMed]

43. Somerville, J.M.; Aspden, R.M.; Armour, K.E.; Armour, K.J.; Reid, D.M. Growth of C57Bl/6 Mice and the Material and Mechanical Properties of Cortical Bone from the Tibia. Calcif. Tissue Int. 2004, 74, 469-475. [CrossRef] [PubMed]

44. Turner, C.H.; Takano, Y.; Owan, I. Aging changes mechanical loading thresholds for bone formation in rats. J. Bone Miner. Res. 2009, 10, 1544-1549. [CrossRef]

45. Hughes, J.M.; Petit, M.A. Biological underpinnings of frost's mechanostat thresholds: The important role of osteocytes. J. Musculoskelet. Neuronal Interact. 2010, 10, 128-135.

46. Schriefer, J.L.; Robling, A.G.; Warden, S.J.; Fournier, A.J.; Mason, J.J.; Turner, C.H. A comparison of mechanical properties derived from multiple skeletal sites in mice. J. Biomech. 2005, 38, 467-475. [CrossRef]

47. Ammann, P.; Rizzoli, A.R. Bone strength and its determinants. Osteoporos. Int. 2003, 14, 13-18. [CrossRef]

48. Lubahn, D.B.; Moyer, J.S.; Golding, T.S.; Couse, J.F.; KoRach, K.S.; Smithies, O. Alteration of reproductive function but not prenatal sexual development after insertional disruption of the mouse estrogen receptor gene. Genetics 1993, 90, 11162-11166. Available online: http:/ / www.pnas.org/content/90/23/11162.full.pdf (accessed on 2 August 2017). [CrossRef]

49. Eddy, E.M.; Washburn, T.F.; Bunch, D.O.; Goulding, E.H.; Gladen, B.C.; Lubahn, D.B.; Korach, K.S. Targeted disruption of the estrogen receptor gene in male mice causes alteration of spermatogenesis and infertility. Endocrinology 1996, 137, 4796-4805. [CrossRef]

50. Rubanyi, G.M.; Freay, A.D.; Kauser, K.; Sukovich, D.; Burton, G.; Lubahn, D.B.; Couse, J.F.; Curtis, S.W.; Korach, K.S. Vascular estrogen receptors and endothelium-derived nitric oxide production in the mouse aorta. Gender difference and effect of estrogen receptor gene disruption. J. Clin. Investig. 1997, 99, 2429-2437. [CrossRef]

51. Bouxsein, M.L.; Boyd, S.K.; Christiansen, B.A.; Guldberg, R.E.; Jepsen, K.J.; Müller, R. Guidelines for assessment of bone microstructure in rodents using micro-computed tomography. J. Bone Miner. Res. 2010, 25, 1468-1486. [CrossRef] [PubMed]

52. Ortinau, L.C.; Linden, M.A.; Dirkes, R.K.; Rector, R.S.; Hinton, P.S. Exercise initiated after the onset of insulin resistance improves trabecular microarchitecture and cortical bone biomechanics of the tibia in hyperphagic Otsuka Long Evans Tokushima Fatty rats. Bone 2017, 103, 188-199. [CrossRef] [PubMed]

53. Ortinau, L.C.; Linden, M.A.; Dirkes, R.; Rector, R.S.; Hinton, P.S. Obesity and type 2 diabetes, not a diet high in fat, sucrose, and cholesterol, negatively impacts bone outcomes in the hyperphagic Otsuka Long Evans Tokushima Fatty rat. Bone 2017, 105, 200-211. [CrossRef] [PubMed] 
54. Doube, M.; Kłosowski, M.M.; Arganda-Carreras, I.; Cordelières, F.P.; Dougherty, R.P.; Jackson, J.S.; Schmid, B.; Hutchinson, J.R.; Shefelbine, S.J. BoneJ: Free and extensible bone image analysis in ImageJ. Bone 2010, 47, 1076-1079. [CrossRef]

55. Bruker-microCT, Morphometric parameters measured by Skyscan ${ }^{\mathrm{TM}}$ CT-Analyser Software. Ref. Man. 2012, 1, 1-49. Available online: http:/ / bruker-microct.com/next/CTAn03.pdf (accessed on 17 March 2019).

56. Jepsen, K.J.; Silva, M.J.; Vashishth, D.; Guo, X.E.; Van Der Meulen, M.C.H. Establishing biomechanical mechanisms in mouse models: Practical guidelines for systematically evaluating phenotypic changes in the diaphyses of long bones. J. Bone Miner. Res. 2015, 30, 951-966. [CrossRef] [PubMed]

57. Turner, C.H.; Burr, D.B. Experimental Techniques for Bone Mechanics. In Bone Mechanics; Taylor and Francis Group: Boca Raton, FL, USA, 2001; pp. 7.1-7.35. Available online: https://doc-04-24-docs.googleusercontent.com/docs/securesc/5bsd23h7nijs0o191 tafmm7te1qj95pc/qkrv573nk7i06q151smbun5sj4uhp211/1560981600000/03597488174621737607/07265225710666323276/1wa2 m7nwhy2gB7Vo0uVu7SAArC8F6NO1E?nonce=e9c26ime80ukc\&user=072652257106663 (accessed on 19 June 2019).

58. Pereira, M.; Gohin, S.; Lund, N.; Hvid, A.; Smitham, P.J.; Oddy, M.J.; Reichert, I.; Farlay, D.; Roux, J.P.; Cleasby, M.E.; et al. Sclerostin does not play a major role in the pathogenesis of skeletal complications in type 2 diabetes mellitus. Osteoporos. Int. 2017, 28, 309-320. [CrossRef] 